\title{
Factors that influence patient preferences for prostate cancer management options: a systematic review
}

This article was published in the following Dove Press journal:

Patient Preference and Adherence

2 July 2015

Number of times this article has been viewed

\section{Timothy N Showalter' \\ Mark V Mishra ${ }^{2}$ \\ John FP Bridges ${ }^{3}$}

'Department of Radiation Oncology, University of Virginia School of

Medicine, Charlottesville, VA, USA; ${ }^{2}$ Department of Radiation Oncology, University of Maryland School of Medicine, ${ }^{3}$ Department of Health Care Policy and Management, Bloomberg School of Public Health, Johns Hopkins University, Baltimore, MD, USA

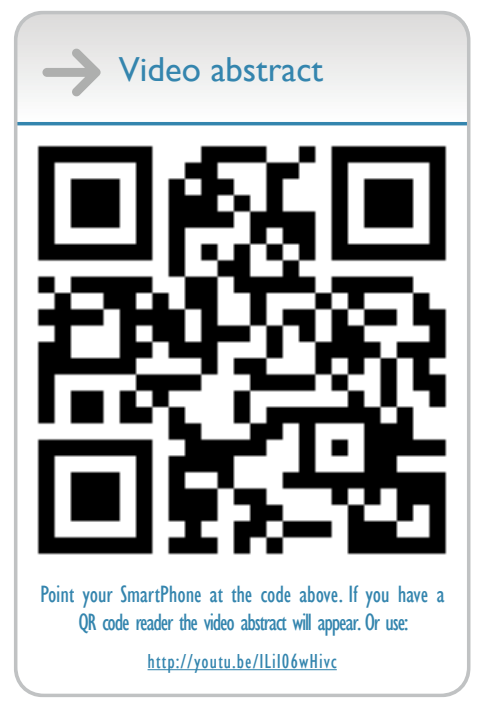

Correspondence: Timothy N Showalter Department of Radiation Oncology, University of Virginia, 1240 Lee Street, Box 800383 , Charlottesville,

VA 22908-0383, USA

Tel +l 4349826278

Fax+l 4342439789

Email tns3b@virginia.edu
Purpose: We performed a systematic review to evaluate evidence regarding factors that influence patient preferences for management options for localized prostate cancer.

Methods: We followed a prespecified search protocol (PROSPERO identifier CRD42014009173) to identify studies that evaluated patient preferences for prostate cancer management options for localized prostate cancer. We queried PubMed, the Cochrane Database of Systematic Reviews, Embase, Cumulative Index to Nursing \& Allied Health Literature (CINAHL) Plus, and Econ-Lit databases. Two separate reviewers completed the article selection process and review, including coding of study characteristics. Study quality was scored according to the PREFS checklist, which consists of five criteria: Purpose, Respondents, Explanation, Findings, and Significance. Reviewers summarized the primary findings of each article included in the analysis.

Results: Of the 606 citations identified in the literature search, there were a total of 21 articles that met all selection criteria, reporting results for a total of 4,131 subjects. Themes identified in the studies included: the importance of patient perceptions of treatment efficacy and side effects; the influence of physician recommendations on patient decision-making; and the prioritization of concerns regarding treatment side effects among those men who prefer radiation therapy or active surveillance. The articles had an average PREFS score of 3.4 (standard deviation [SD] 1.0 ), which is similar to a recent study for breast cancer treatment preferences.

Conclusion: This systematic review of factors that influence patient preferences for prostate cancer management options identified a small, but high quality, group of articles that satisfied the selection criteria. The available evidence suggests that interventions aimed at informing patients regarding the comparative effectiveness of prostate cancer management alternatives should include the influence of physician recommendations and family members' desires on patient decision-making.

Keywords: prostate cancer, treatment, decision making, preferences, patient

\section{Introduction}

It is estimated that over 230,000 men will be diagnosed with prostate cancer in the US each year, ${ }^{1}$ and the majority of these men will receive definitive treatment for localized prostate cancer (LPC). ${ }^{2}$ Management options for LPC include active surveillance (AS), radical prostatectomy (RP), external beam radiation therapy, and brachytherapy. ${ }^{3}$ Treatment decisions are particularly challenging due to a lack of patient-centered comparative effectiveness research, and the similar impact of surgical and radiation management options on both cure rates and quality of life indicators. , $^{3,4}$

LPC patients play an important role in making their own management decisions. Individualized treatment decisions are influenced by patient perception of treatmentrelated side effects and their personal beliefs regarding the effectiveness and tolerance 
of management options..$^{5-7}$ Since there are multiple management options with similar benefits and harms, and clinical evidence is uncertain, LPC management decisions are considered "preference-sensitive" ${ }^{8,9}$ Although the importance of considering patient preferences for LPC management decisions has been recognized in the literature, ${ }^{10-13}$ there is little consensus regarding how to incorporate this into research or clinical applications. The heterogeneity in the definition and measurement of patient preferences presents a challenge for synthesizing and evaluating the published literature.

Despite the challenges involved in considering patient preferences, this is a worthwhile objective for informing LPC management decisions. In decision analytic models, incorporation of patients' individual-level utility values, rather than average group-level estimates, for treatment outcomes has been shown to change the model-recommended management choice in $25 \%-48 \%$ of cases. ${ }^{10}$ Information regarding patients' preferences outcomes associated with prostate cancer management options has the potential to influence patient-centered outcomes research and clinical applications of decision aids and shared decision-making interventions. Zeliadt et al contributed a 2006 review of factors that influence patient decision-making for LPC, which included selected reports published between 1990 and 2004. ${ }^{14}$ The current report aims to update the available information on patient preferences for LPC management options in the contemporary era and to evaluate the quality of published studies.

A 2013 Institute of Medicine (IOM) report on highquality cancer care emphasizes the importance of considering the preferences and values of individual cancer patients during advanced care planning. ${ }^{15}$ Since clear communication and insights into patient preferences are an essential part of providing quality patient-centered care, ${ }^{15,16}$ this review provides a meaningful starting point in understanding patient decision-making for clinicians who care for LPC patients. The primary objective of this systematic review was to identify and describe the methods and findings of published qualitative and quantitative studies focused on factors that influence patient preferences for management of LPC. The definition of preferences, structure of the review protocol, and evidence quality assessment strategy were based upon a prior report by Joy et al. ${ }^{17}$

\section{Methods}

\section{Literature search and study selection}

A systematic review was performed according to a prespecified review protocol that was registered in the PROSPERO international register of systematic reviews
(http://www.crd.york.ac.uk/PROSPERO/). The review protocol is accessible on the PROSPERO register (PROSPERO identifier CRD42014009173). We searched PubMed, the Cochrane Database of Systematic Reviews, Embase, Cumulative Index to Nursing \& Allied Health Literature (CINAHL) Plus, and Econ-Lit databases to identify studies that evaluate patient preferences for prostate cancer management options for LPC. The literature search was performed on April 2, 2014. The full PubMed search strategy is displayed in Table $\mathrm{S} 1$, and similar searches were conducted in the other databases. The search strategy focused on use of keyword search terms to identify studies based on diagnosis (eg, "prostate cancer"), stage (eg, "localized” OR “organ-confined”), treatment (eg, "treatment” OR "radiation" OR “surgery"), and preference assessment method (eg, "stated preference" OR "preferences" OR "discrete choice").

Eligible studies for inclusion in the final analysis set were those that evaluated the preferences of adult LPC patients for prostate cancer management options. Any comparisons of management options, including AS and watchful waiting, were considered eligible. Participants must have been engaged in the study from a personal perspective, but were not required to have been diagnosed with LPC for the study to be included. In other words, studies that presented hypothetical scenarios to healthy male participants or participants at high risk of prostate cancer were included, since all subjects were at risk for prostate cancer. This inclusion was based upon prior studies showing similar stated preferences for both elderly males with LPC and those not diagnosed with LPC. ${ }^{18,19}$ Studies that evaluated only the preferences of individuals other than patients, such as spouses or caregivers, were excluded. Studies of patient preferences for screening or biopsy, or for choices regarding metastatic prostate cancer, were excluded. Studies were excluded if they lacked original data, or were on a topic other than prostate cancer, or did not focus upon preferences for management options. The search was limited to studies published from 1995 to the search date to ensure the studies represented contemporary management options. Although surgical and radiotherapeutic techniques have changed during the study period of 1995-2014, this range is reasonable from the clinical perspective because the technical advances have not been shown to clearly improve outcomes. ${ }^{20}$ The prior 2006 review of patient preferences for treatment options published by Zeliadt et al includes studies published during 1990 or later. ${ }^{14}$ The search was limited to English language articles.

After the initial search, article titles were evaluated for relevance and potential exclusion. Duplicate studies were 
excluded. Two reviewers performed the review and exclusion process separately (TNS and MVM); both reviewers must have agreed for an article to be excluded. In the event of initial disagreement, the two reviewers discussed until consensus was reached. The articles that passed title review proceeded to abstract review, and then the abstracts included for manuscript review were subjected to full review of the article. The final study set of articles for inclusions in the quality assessment was defined at the end of this stepwise process.

\section{Data abstraction and assessment}

A data abstraction form was developed based on review of the first article from among the group selected for inclusion in the study. Data abstraction was performed separately by two reviewers (TNS and MVM). Data elements collected included: publication year, authors, journal name, title, number of participants, eligibility criteria for participants, preference assessment method(s), number of attributes of management options considered, number of management options included, subgroup analyses performed, funding source, responses to the quality assessment checklist, and primary findings or conclusions. The review of primary findings or themes was open-ended, without a prespecified coding system, and intended to describe the primary conclusions of the study authors. Preference assessment method was categorized in a fashion similar to that reported by Joy et al: ${ }^{17}$ time trade-off, standard gamble, discrete choice experiment, contingent evaluation, stated preference (other) (SPO), or qualitative. One reviewer (TNS) developed the coding form and iteratively refined the form with a pilot sample of articles. The two reviewers discussed the results after coding separately and reached consensus through discussion. The two reviewers did not complete a formal evaluation of inter-rater reliability and consensus was readily reached.

The Purpose, Respondents, Explanation, Findings, and Significance (PREFS) quality assessment checklist was previously developed by Dr Bridges et al for assessing quality of reports in systematic reviews of literature on patient preferences. ${ }^{17}$ The PREFS checklist comprises questions regarding five aspects of each study: purpose $(\mathrm{P})$, respondents (R), explanation (E), findings (F), and significance (S) $\cdot{ }^{17}$ The complete PREFS checklist questions are shown in Table S2. A quality score was calculated by adding one point for each "Yes" answer on the PREFS checklist, with a maximum potential score of 5 . The reviewers separately provided yes or no answers on the PREFS checklist and consensus was reached through discussion.

\section{Descriptive analysis}

The primary characteristics of the included studies were summarized and described. In addition, the primary themes and conclusions from each study were presented based on reviewers' identification of the reported conclusions from each study and each study's stated relationships between factors and preferences. Descriptive analysis was performed to present the proportion of studies with each characteristic. Given the small sample size and heterogeneous study methodologies, no statistical comparisons were performed.

\section{Results}

A total of 606 titles were identified in the initial database searches (performed on April 2, 2014), and the study selection results are summarized in Figure 1. After excluding reports published prior to $1995(\mathrm{n}=17)$, duplicate titles $(\mathrm{n}=63)$, and reports published in languages other than English $(n=32)$, there were 494 titles for title review (Figure 1). After title review to exclude irrelevant reports, there were 212 articles remaining for abstract review. Abstracts were then reviewed to identify 61 manuscripts for full manuscript review after study exclusions. An additional ten articles were added at this stage based upon the authors' knowledge of a recent study not identified in the search, ${ }^{21}$ review of the references from a prior review article on the patient preferences for prostate cancer treatment, ${ }^{14}$ and review of all references of the articles selected for full manuscript review. Therefore, a total of 71 manuscripts were reviewed. After exclusions, there were a total of 21 articles included that met all study criteria, including three articles from among the ten that were added in at the stage of full manuscript review. These 21 articles comprised the analysis set (Figure 1), and represented a total of 4,131 subjects.

\section{Study characteristics}

Among the 21 studies that met all eligibility requirements for the review, the majority of studies $(67 \%)$ and individual subjects $(70 \%)$ were from the US. The mean number of subjects per study was 233 (range: $21-768$ ). The most common methodology used was SPO (13), followed by qualitative (6), time trade-off (2), and discrete choice experiment (1). The majority of studies were funded by governmental and foundation sources, and only one study reported industry support. When subgroups were evaluated in the studies, it was most commonly based upon management choice. The number of management options considered in each study ranged from two to nine, with an average of 3.8 (standard deviation [SD] 1.8). The most commonly presented management options were AS, prostatectomy, external beam radiation therapy, and brachytherapy. Other treatment alternatives, such as 


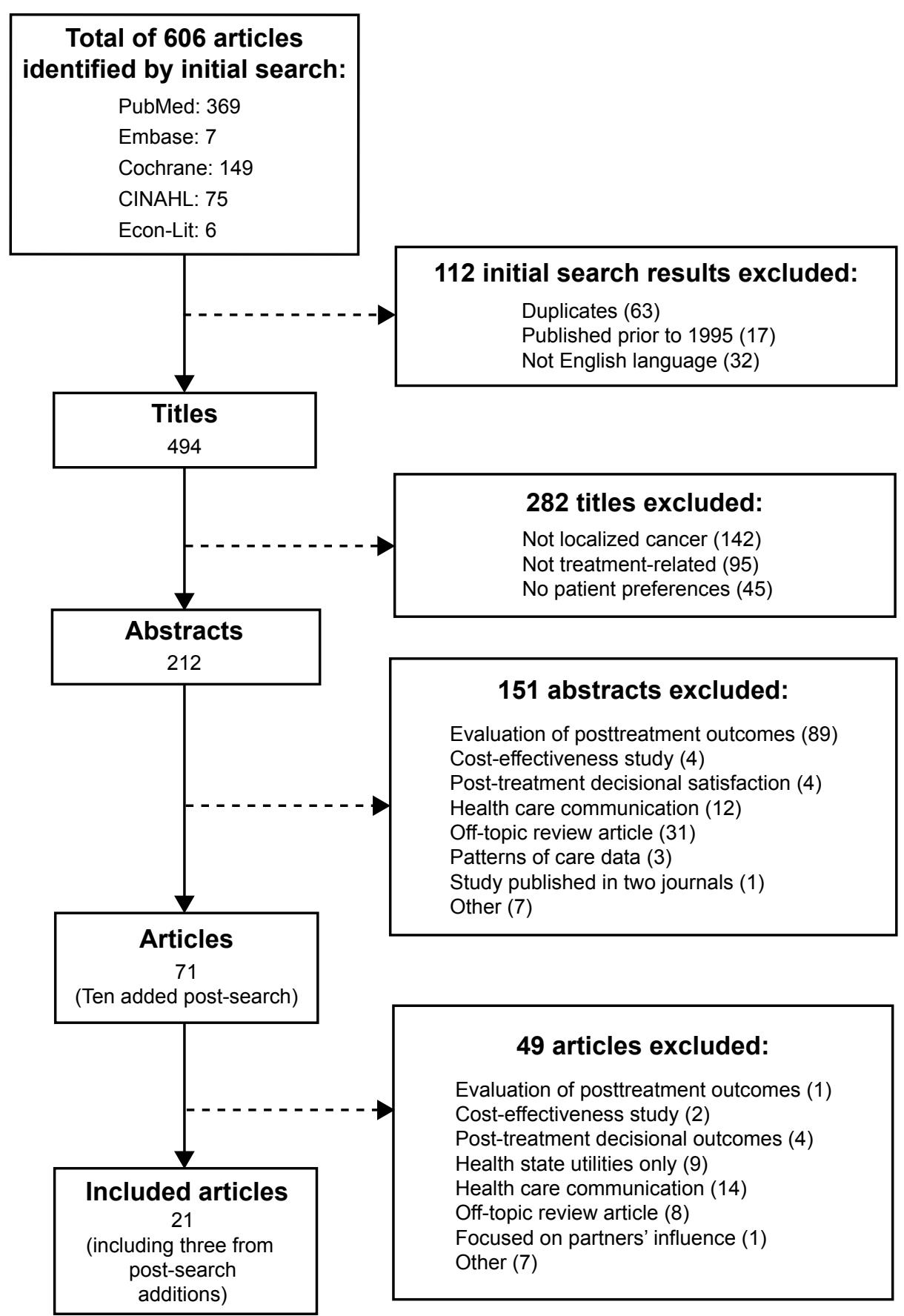

Figure I Study selection results.

Abbreviation: CINAHL, Cumulative Index to Nursing \& Allied Health Literature.

cryotherapy and high-frequency ultrasound treatment, were evaluated infrequently. The number of attributes of treatments evaluated ranged widely from four to 24 (mean 8.8, SD 5.9). Examples of attributes included in the studies include perceived likelihood of cure, risks of side effects, perceived invasiveness of the treatment, treatment schedule, and physician recommendation. Four of the qualitative studies did not limit the number of potential attributes of the management options discussed, since the methodology permitted open-ended discussion during semi-structured interviews. More studies were published in the latter half of the study period than in the earlier years (Figure S1). The number of studies per year ranged from zero to four articles, and the density of articles was greatest during 2010 through 2013, when two to four articles were published annually. Study characteristics are summarized in Table 1. 


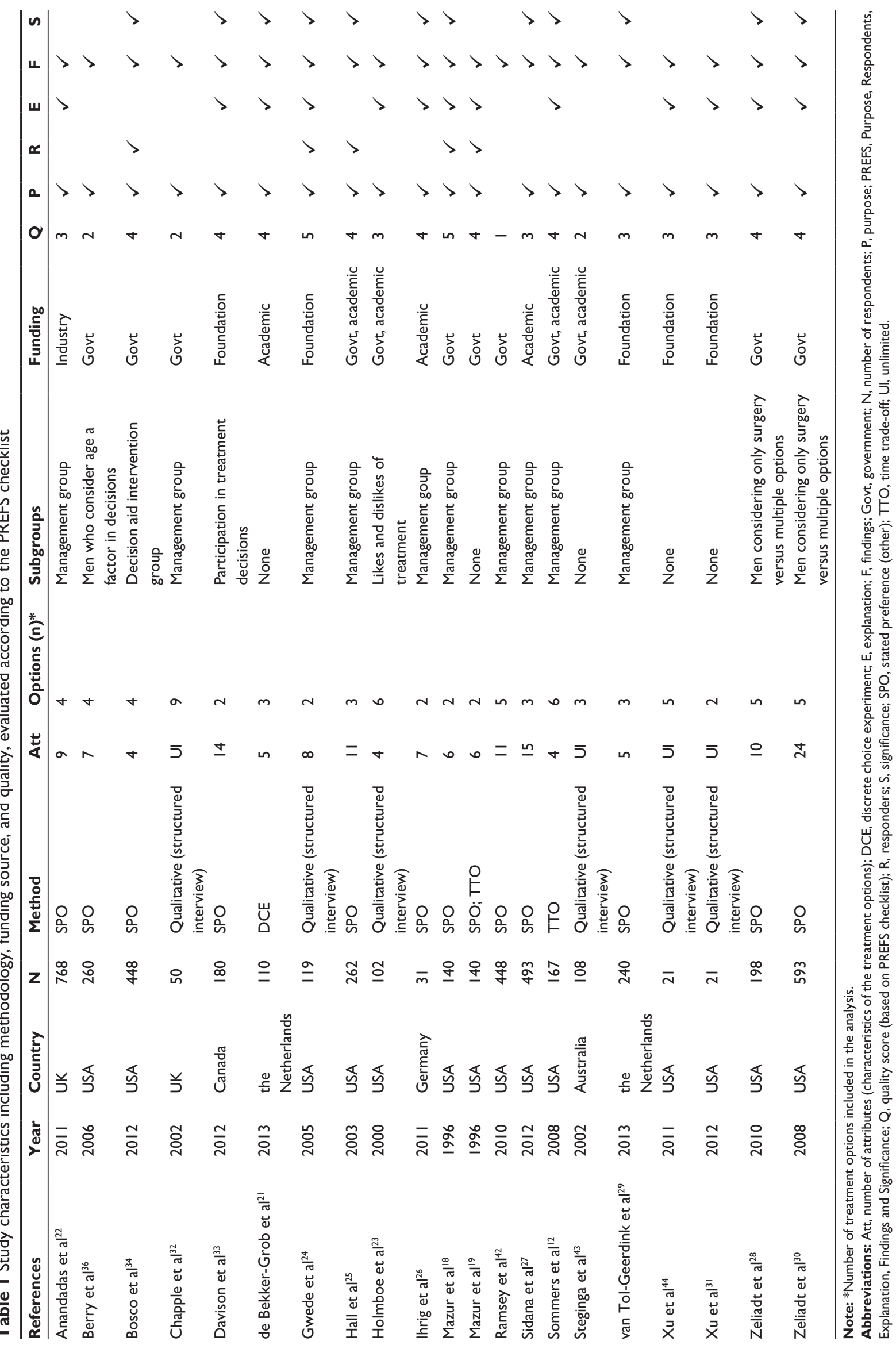




\section{Themes of preferences among management options}

A number of themes and primary conclusions were identified, and the full list for all 21 articles is shown in Table S3. Men who preferred RP generally valued physical removal of the cancer ${ }^{18,22,23}$ and believed that RP offered higher cure rates. ${ }^{24-28}$ A recurrent theme for men who preferred external beam radiation therapy or brachytherapy was a desire to avoid urinary and sexual complications of surgery. ${ }^{21,24-30}$ Men who preferred AS over active treatment options valued the avoidance of the complications of RP, ${ }^{18,19}$ and also reported facing pressure from physicians and family members to choose active treatment over AS. ${ }^{31,32}$ In addition to patients' perceptions of treatment efficacy and side effects, respondents also reported a significant influence of physician recommendations regarding management options. ${ }^{12,25,27,31,33}$ Interestingly, two studies found that most patients stated a preference for a management option that did not match their stated prioritization of concerns regarding potential complications ${ }^{34}$ or quality-adjusted life years for health states. ${ }^{12}$ Holmboe et al noted that patients cited intrinsic characteristics (eg, duration of therapy and invasiveness) of treatment alternatives more frequently than the probabilities of treatment-related adverse effects. ${ }^{23}$

\section{PREFS checklist assessment and quality score}

The mean PREFS quality score was 3.4 (SD 1.0), and the scores ranged from 1 to 5 . The mean quality scores were 2.7 (SD 1.3) among studies with qualitative methods and 3.7 (SD 0.8) among studies with SPO methods. All of the 22 studies included all respondents in the evaluation of findings ( $F$ domain), and 21 of 22 studies explicitly stated that the purpose ( $\mathrm{P}$ domain) of the study was to evaluate patient preferences for prostate cancer management options. There was more variability among the studies in satisfying the $\mathrm{R}$, E, and S domains of the PREFS checklist (Table 1), demonstrating that many reports lacked details regarding whether responders were similar to nonresponders and the preference assessment methods used, and failed to include statistical tests to evaluate results.

There were two studies that received a PREFS quality score of 5. ${ }^{18,24}$ One of these studies, reported by Gwede et al, applied a qualitative method using structured interviews with 119 men. ${ }^{24}$ The other study with a PREFS quality score of 5 was reported by Mazur et $\mathrm{al}^{18}$ and the method of preference assessment was categorized as SPO. The methodological approach involved a structured interview process using a written scenario to guide a decision between RP and AS and a set of predetermined questionnaires. Both studies were conducted in the US with the support of government or foundation research funding.

\section{Discussion}

This systematic review of the literature on factors that influence the preferences of patients and at-risk males for LPC management options identified a total of 21 articles that satisfied prespecified search criteria, representing the measured preferences of a total of 4,131 subjects. The total number of subjects in the current systematic review is relatively large, with a mean 233 subjects per study. Many of the major findings and themes were also consistent among the studies, suggesting that a larger number of articles would be unlikely to further elucidate patients' preferences for LPC management options. The average PREFS quality score in our review (3.4) is similar to the average PREFS score (3.5) observed by Hamelinck et al in their systematic review of patients' preferences for adjuvant systemic therapy options for breast cancer ${ }^{35}$ and higher than the average PREFS score (2.7) observed by Joy et al in their review of diabetes mellitus treatment options. ${ }^{17}$ This suggests that the available studies on the influence of factors on preferences for LPC management options are generally of good quality, but lack some elements such as comparisons of respondents versus nonrespondents and performance of statistical tests to evaluate significance of findings. There was a relatively wide range of study methods and a high rate of government, academic, and foundation funding, providing a broad perspective without a major concern for conflicts of interest related to industry funding. The body of articles identified in the current review, therefore, represents a relatively large amount of studies with good quality that provides useful insights into patient preferences for LPC management options.

The themes identified in this review highlight salient factors that contribute to patients' management decisions. These themes provide clinicians a framework for addressing the IOM 2013 recommendation ${ }^{15}$ to consider patient preferences when planning cancer management. Primary themes identified in this review included: the strong influence of physician and family member recommendations on treatment decisions, particularly when patients favor AS; that patients often choose a management option based on the perception that their selection is clearly more effective than the other available alternatives at curing prostate cancer; and, on the other hand, that patients' perceptions of the likelihood of side effects was a major determinant of management preferences. 
Although subjects were engaged from a perspective focused on their own personal preferences, the influence of physicians and family members emphasizes the key role of external players in the decision-making process. The coexistence of primary themes regarding perceived effectiveness at curing prostate cancer and concern regarding side effects is emblematic of the complex, multifaceted decision that patients face when considering LPC management options.

Patients who preferred AS or radiation therapy tended to prioritize concerns regarding side effects over cure. Although the decision-making process is complex, this observation demonstrates that some men place a value on risk of side effects that outweighs concerns regarding physical removal of the prostate gland or perceived effectiveness at achieving cure. Several articles observed that patients placed a priority on the risks of impotence from LPC treatments. ${ }^{23,36,37}$ This finding suggests a need for in-depth evaluation of implications for patient perceptions of their own sexuality and masculine identity. Ramsey et al evaluated the longitudinal impact of prostate cancer treatments on sexual relationships and observed a significant negative impact that worsened over time during the first year after cancer treatment. ${ }^{38}$

Interestingly, two studies that compared patient management choices to estimated ideal choices based on stated preferences for side effects demonstrated a low rate of concordance with the ultimate treatment choice (Table S3). AS is preferred over active treatment for many patients with favorable-risk LPC, ${ }^{3,39}$ but it has been shown that the utilization of AS is lower than expected. ${ }^{40,41}$ Barriers to patients' choosing AS have been shown to include limited published evidence regarding outcomes with AS and the influence of physicians who recommend treatment with surgery or radiation therapy. ${ }^{7}$ Based on these considerations, patientcentered educational tools or decision-making interventions should also include the physicians and family members who are influential to patients. That patients report choosing the LPC management option that is most effective may reflect an area of uncertainty and potential need for unbiased medical guidance. It is possible that physician recommendations for certain treatments are a primary driver for patient perceptions of superiority of a single option. The best available evidence on LPC management options suggests that there is no single treatment option with better cure rates or quality of life than the rest. ${ }^{3,4}$ It is important that information resources for LPC management decisions should, therefore, emphasize that no single management option has been clearly shown to be best. Finally, potential decision aids must not assume that preference for management outcomes and health states can be used in a direct fashion to guide patients' therapeutic choices, since the current review includes two studies that reveal that patients do not necessarily choose management options based solely upon a rational consideration of priorities for potential side effects. The decision-making process is complex for LPC patients choosing among the various management options, and the themes identified in this review detail the numerous potential considerations that are important to patients.

The current review focuses exclusively on patient preferences among management options, providing a list of factors that influence preferences of patients and at-risk men among the therapeutic alternatives for LPC. This is a more restrictive approach than used in a prior review by Zeliadt et $\mathrm{al}^{14}$ which also included studies that reported only on partner preferences for management options or patient preferences for treatment-related health states. The current review was designed such that the articles were restricted to only those that directly addressed LPC management decision-making in a way that was directly focused on the perspectives of individual patients, with the goal of informing future approaches toward guiding clinical discussions with patients faced with management decisions.

However, there are important limitations to the current study that should be considered. During the study selection process, ten articles were identified outside of the original search strategy for full manuscript review, and three of these articles were included in the final set of 21 articles. The identification of articles from outside the original literature search suggests some limitations in the search strategy. The current review was primarily descriptive, providing an overview and quality rating of the relevant studies. Our review identified some limitations to the available evidence. In addition to an underrepresentation of men outside the US, there were a relatively small number of reports (one of 21) that factored patient age into consideration of patient preferences. By excluding articles written in languages other than English, it is possible our review missed some potential additional insights. Our review demonstrates a potential overrepresentation of data from the US, since the majority of studies were conducted in the US. This review did not identify research regarding the influence of chronic illnesses and other medical comorbidities on patient preferences for treatment, even though this factors into clinical practice guidelines for LPC treatment decisions. ${ }^{3}$ Finally, the current review does not directly address changes over time in expectant management or the technical details of prostatectomy and radiation therapy. During the study period, expectant management changed significantly from watchful waiting to a more 
rigorous approach for contemporary AS, and these changes were not considered in the analysis. Watchful waiting is now recommended in treatment guidelines only for patients with limited life expectancy. ${ }^{3}$

\section{Conclusion}

In conclusion, the current systematic review describes the existing literature on patient preferences for LPC management options. This study provides a survey of the existing evidence, demonstrates relatively high study quality using the PREFS scale for preference assessment studies, and identifies several important themes regarding patient preferences for management options. Primary themes identified included: a significant influence of physicians and family members on patient preferences for AS, that patients believe their chosen management option is more effective than the alternatives, and that some patients who choose AS or radiation therapy report prioritizing risk of side effects in their decision-making. This review provides descriptive information regarding influences upon patient decision-making for management alternatives. Future work should expand upon this foundation by delivering tailored information to patients that provides personalized information to address their individual goals and priorities for outcomes.

\section{Acknowledgment}

This work was performed with the support of a 2011 Ben Franklin Young Investigator Award from the Prostate Cancer Foundation (TNS).

\section{Disclosure}

The authors report no conflicts of interest in this work.

\section{References}

1. Siegel R, Ma J, Zou Z, et al. Cancer statistics, 2014. CA Cancer J Clin. 2014;64:9-29.

2. Cooperberg MR, Broering JM, Kantoff PW, et al. Contemporary trends in low-risk prostate cancer: risk assessment and treatment. $J$ Urol. 2007;178(3 Pt 2):S14-S19.

3. NCCN Guidelines. Prostate Cancer. Fort Washington, PA: NCCN Guidelines; 2015.

4. Sanda MG, Dunn RL, Michalski JM, et al. Quality of life and satisfaction with outcome among prostate-cancer survivors. $N$ Engl J Med. 2008; 358(12):1250-1261.

5. Jansen SJT, Kievit J, Nooij MA, et al. Patients' preferences for adjuvant chemotherapy in early-stage breast cancer: is treatment worthwhile? Br J Cancer. 2001;84(12):1577-1585.

6. Zeguers M, de Haes HCJM, Zandbelt LC, et al. The information needs of new radiotherapy patients: How to measure? Do they want to know everything? And if not, why? Int J Radiat Oncol Biol Phys. 2012;82(1):418-424.

7. Mishra MV, Bennett M, Vincent A, et al. Identifying barriers to patient acceptance of active surveillance: content analysis of online patient communications. PLoS One. 2013;8(9):e68563.
8. Kramer KM, Bennett CL, Pickard AS, et al. Patient preferences in prostate cancer: a clinician's guide to understanding health utilities. Clin Prostate Cancer. 2005;4(1):15-23.

9. O'Connor AM, Llewellyn-Thomas HA, Flood AB. Modifying unwarranted variations in health care: shared decision making using patient decision aids. Health Aff. 2004; Suppl Variation:Var63-V72.

10. Cowen ME, Miles BJ, Cahill DF, et al. The danger of applying grouplevel utilities in decision analyses of the treatment of localized prostate cancer in individual patients. Med Decis Making. 1998;18:376-380.

11. Sommers BD, Beard CJ, D'Amico AV, et al. A decision analysis using individual patient preferences to determine optimal treatment for localized prostate cancer. Cancer. 2007;110:2210-2217.

12. Sommers BD, Beard CJ, D'Amico AV, Kaplan I, Richie JP, Zeckhauser RJ. Predictors of patient preferences and treatment choices for localized prostate cancer. Cancer. 2008;113:2058-2067.

13. Lubeck DP, Grossfeld GD, Carroll PR. A review of measurement of patient preferences for treatment outcomes after prostate cancer. Urology. 2002;60(Suppl 3A):72-78.

14. Zeliadt SB, Ramsey SD, Penson DF, et al. Why do men choose one treatment over another?: a review of patient decision making for localized prostate cancer. Cancer. 2006;106(9):1865-1874.

15. IOM (Institute of Medicine). Delivering High-Quality Cancer Care: Charting a New Course for a System in Crisis. Washington, DC: IOM; 2013.

16. Balogh EP, Ganz PA, Murphy SB, et al. Patient-centered cancer treatment planning: improving the quality of oncology care. Summary of an Institute of Medicine workshop. Oncologist. 2011;16:1800-1805.

17. Joy SM, Little E, Maruthur NM, et al. Patient preferences for the treatment of type 2 diabetes: a scoping review. PharmacoEconomics. 2013;31:877-892.

18. Mazur DJ, Hickam DH. Patient preferences for management of localized prostate cancer. West J Med. 1996;165(1-2):26-30.

19. Mazur DJ, Hickam DH, Mazur MD. How patients' preferences for risk information influence treatment choice in a case of high risk and high therapeutic uncertainty: asymptomatic localized prostate cancer. Med Decis Making. 1999;19(4):394-398.

20. Wilt TJ, MacDonald R, Rutks I, et al. Systematic review: comparative effectiveness and harms of treatments for clinically localized prostate cancer. Ann Intern Med. 2008;148(6):435-448.

21. de Bekker-Grob EW, Bliemer MC, Donkers B, et al. Patients' and urologists' preferences for prostate cancer treatment: a discrete choice experiment. Br J Cancer. 2013;109:633-640.

22. Anandadas CN, Clarke NW, Davidson SE, et al. Early prostate cancer - which treatment do men prefer and why? BJU Int. 2011; 107(11):1762-1768.

23. Holmboe ES, Concato J. Treatment decisions for localized prostate cancer: asking men what's important. J Gen Intern Med. 2000; 15:694-701.

24. Gwede CK, Pow-Sang J, Seigne J, et al. Treatment decision-making strategies and influences in patients with localized prostate carcinoma. Cancer. 2005;104(7):1381-1390.

25. Hall JD, Boyd JC, Lippert MC, et al. Why patients choose prostatectomy or brachytherapy for localized prostate cancer: results of a descriptive survey. Urology. 2003;61:402-407.

26. Ihrig A, Keller M, Hartmann M, et al. Treatment decision-making in localized prostate cancer: why patients chose either radical prostatectomy or external beam radiation therapy. BJU Int. 2011;108:1274-1278.

27. Sidana A, Heranndez DJ, Feng Z, et al. Treatment decision-making for localized prostate cancer: what younger men choose and why. Prostate. 2012;72(1):58-64.

28. Zeliadt SB, Moinpour CM, Blough DK, et al. Preliminary treatment considerations among men with newly diagnosed prostate cancer. Ame J Manag Care. 2010;16(5):e121-e130.

29. van Tol-Geerdink JJ, Willem Leer J, Weijerman PC, et al. Choice between prostatectomy and radiotherapy when men are eligible for both: a randomized controlled trial of usual care vs decision aid. BJU Int. 2013;111(4):564-573. 
30. Zeliadt SB, Ramsey SD, Potosky AL, et al. Association of preexisting symptoms with treatment decisions among newly diagnosed prostate cancer patients. Patient. 2008;1(3):189.

31. Xu J, Neale AV, Dailey RK, Eggly S, Schwartz KL. Patient perspective on watchful waiting/active surveillance for localized prostate cancer. J Am Board Fam Med. 2012;25(6):763-770.

32. Chapple A, Ziebland S, Herxheimer A, et al. Is 'watchful waiting' a real choice for men with prostate cancer? A qualitative study. BJU Int. 2002;90:257-264.

33. Davison BJ, Breckon E. Factors influencing treatment decision making and information preferences of prostate cancer patients on active surveillance. Patient Educ Couns. 2012;87:369-374.

34. Bosco JL, Halpenny B, Berry DL. Personal preferences and discordant prostate cancer treatment choice in an intervention trial of men newly diagnosed with localized prostate cancer. Health Qual Life Outcomes. 2012;10:123-123.

35. Hamelinck VC, Bastiaannet E, Pieterse AH, et al. Patients' preferences for surgical and adjuvant systemic treatment in early breast cancer: a systematic review. Cancer Treat Rev. 2014;40(8):1005-1018.

36. Berry DL, Ellis WJ, Russell KJ, et al. Factors that predict treatment choice and satisfaction with the decision in men with localized prostate cancer. Clin Genitourin Cancer. 2006;5(3):219-226.

37. Ramsey SD, Zeliadt SB, Fedorenko CR, et al. Patient preferences and urologist recommendations among local-stage prostate cancer patients who present for initial consultation and second opinions. World J Urol. 2011;29(1):3-9.
38. Ramsey SD, Zeliadt SB, Blough DK, et al. Impact of prostate cancer on sexual relationships: a longitudinal perspective on intimate partners' experiences. $J$ Sex Med. 2013;10(12):3135-3143.

39. Hayes JH, Ollendorf DA, Pearson SD, et al. Active surveillance compared with initial treatment for men with low-risk prostate cancer: a decision analysis. JAMA. 2010;304(21):2373-2380.

40. Cooperberg MR, Broering JM, Carroll PR. Time trends and local variation in primary treatment of localized prostate cancer. J Clin Oncol. 2010;28(7):1117-1123.

41. Mishra MV, Shen X, Den RB, et al. Patterns of care for elderly men diagnosed with favorable-risk prostate cancer from 2004 to 2008 : a population-based analysis. Am J Clin Oncol. 2013;36(6):606-611.

42. Ramsey SD, Zeliadt SB, Arora NK, et al. Unanticipated and underappreciated outcomes during management of local stage prostate cancer: a prospective survey. J Urol. 2010;184(1):120-125.

43. Steginga SK, Occhipinti S, Gardiner RA, et al. Making decisions about treatment for localized prostate cancer. BJU Int 2002;89(3):255-260.

44. Xu J, Neale AV, Dailey RK, et al. Patient perspective on watchful waiting/active surveillance for localized prostate cancer. J Am Board Fam Med. 2012;25(6):763-770. 


\section{Supplementary materials}

Table SI Search strategy listed according to class of search terms

\begin{tabular}{|c|c|}
\hline Class of search terms & Terms used \\
\hline \multirow[t]{2}{*}{ Diagnosis } & "Prostate cancer" OR "prostate carcinoma" OR "prostate adenocarcinoma" OR ["prostate" AND ("cancer" OR \\
\hline & “carcinoma” OR “adenocarcinoma” OR “malignant” OR “neoplasm”)] \\
\hline \multirow[t]{2}{*}{ Stage } & "Localized" OR “organ-confined" OR “curative" OR “definitive” OR “encapsulated” OR “local” OR "nonmetastatic" \\
\hline & OR "non-metastatic" OR “early stage" OR "early-stage" \\
\hline \multirow[t]{2}{*}{ Treatment } & "Treatment" OR "therapy" OR "management" OR "surveillance" OR "watchful waiting" OR "radiation" OR "surgery" \\
\hline & OR "prostatectomy" OR "brachytherapy" \\
\hline \multirow[t]{5}{*}{ Preference assessment } & "Conjoint analysis" OR "satisfaction" OR "choice model" OR "stated preference" OR "discrete choice" OR "DCE" OR \\
\hline & "decision analysis" OR "preferences" OR "multi-criteria decision analysis" OR “MCDA" OR "multi-attribute utility" OR \\
\hline & "analytic hierarchy process" OR "trade off" OR "self-explicated" OR "best-worst scaling" OR "utilities" OR "preference \\
\hline & weight" OR "willingness to pay" OR "WTP" OR "willingness to accept" OR "contingent valuation" OR "priorities" OR \\
\hline & "valuation" \\
\hline
\end{tabular}

Note: Each class was listed with "AND” between the classes.

Table S2 PREFS checklist for assessing quality of preference assessment reporting in the manuscripts included in the review

\begin{tabular}{ll}
\hline Question & Answer \\
\cline { 2 - 2 } & No/not clear \\
\hline $\begin{array}{l}\text { Purpose: Is the purpose of the } \\
\text { study in relation to preferences } \\
\text { clearly stated? }\end{array}$ & $\begin{array}{l}\text { The purpose/research question/objectives/ } \\
\text { aim does not mention preference, but may } \\
\text { mention satisfaction, quality of life, ratings, } \\
\text { acceptance }\end{array}$ \\
Respondents: Are the & Evidence of significant differences OR \\
responders similar to the & No assessment of the difference between \\
nonresponders? & $\begin{array}{l}\text { responders and nonresponders OR } \\
\text { Responders are compared only to a target }\end{array}$ \\
Explanation: Are methods of & population rather than nonresponders \\
assessing preferences clearly & The question(s) or response options are not \\
explained? & clear
\end{tabular}
explained?

\begin{tabular}{ll} 
Answer & Yes \\
\hline No/not clear & Any reference in the research question/objectives/ \\
The purpose/research question/objectives/ & aim to preference, utility/disutility, willingness to pay, \\
aim does not mention preference, but may & importance, priorities, goals, revealed preference \\
mention satisfaction, quality of life, ratings, & (eg, choice to continue) \\
acceptance & Any evidence that the responders do not differ \\
Evidence of significant differences OR & significantly from the nonresponders \\
No assessment of the difference between &
\end{tabular}

Responders are compared only to a target population rather than nonresponders The question(s) or response options are not The actual preference question is reported in the text or an appendix, or if it is referenced and available elsewhere, and if it is clear what response options were available to respondents, even if the mode of the question (eg, written, oral, online) is not clear OR

For studies with multiple questions relating to preferences such as conjoint/discrete choice studies, it is clear what was presented to respondents and what responses were available

All respondents who completed the preference question were included in the analysis $O R$

Some responses are excluded from the
analysis and the possibility of this introducing systematic bias has not been ruled out OR It is not clear whether all respondents were included in the analysis

For studies with multiple questions relating to preferences such as conjoint/discrete choice studies, all respondents who at least partially completed the preference questions were included in the analysis $O R$

If some respondents who at least partially completed the preference questions were excluded from the analysis (eg, non-traders, lexicographic preferences, failed test question, irrational preferences, did not complete) AND there is any evidence that those excluded do not differ significantly from those included The study reports $P$-values, $P$-value ranges (eg, $P<0.05$ ), confidence intervals, means with standard deviations or standard errors in relation to the preference results (eg, testing the preference hypotheses or study objectives)
The study reports only proportions, counts, graphs, etc
Significance: Were significance tests used to assess the preference results? 
Table S3 Major findings and themes presented in each of the articles included in the review

\begin{tabular}{|c|c|}
\hline References & Major findings or themes \\
\hline Anandadas et $\mathrm{al}^{2}$ & $\begin{array}{l}\text { Most men who chose RP wanted physical removal of the cancer (60\%). Approximately } 27 \% \text { of men who chose EBRT did } \\
\text { so from fear of other treatment options. The main reason for choosing BT was more convenient for their lifestyle ( } 39 \%) \text {. }\end{array}$ \\
\hline Berry et $\mathrm{al}^{3}$ & $\begin{array}{l}\text { Personal perceptions of outcomes were highly influential. Longevity and bowel, bladder, and sexual function concerns } \\
\text { most influential. Impact on work and recreation activities also influential. Majority ( } 70 \%) \text { reported a specific influence } \\
\text { of age on treatment outcomes. }\end{array}$ \\
\hline Bosco et $\mathrm{al}^{4}$ & $\begin{array}{l}\text { When side effects influenced treatment decisions, most commonly combination of all three (bowel, bladder, and } \\
\text { sexual) rather than one or two. Less than half of patients chose treatment option concordant with stated concerns. }\end{array}$ \\
\hline Chapple et $\mathrm{al}^{5}$ & This qualitative study found that men who choose AS face pressure from family members to pursue active treatment. \\
\hline Davison et $\mathrm{al}^{6}$ & $\begin{array}{l}\text { Four main factors influenced management decisions: urologist's recommendation, impact of treatment on urinary } \\
\text { function, age at time of diagnosis, and impact of treatment on sexual function. }\end{array}$ \\
\hline de Bekker-Grob et $\mathrm{al}^{7}$ & $\begin{array}{l}\text { Patients with anxious/depressed feeling were more likely to choose EBRT or RP than AS. Management choices were } \\
\text { influenced by treatment modality and risk of urinary incontinence. }\end{array}$ \\
\hline Gwede et $\mathrm{al}^{8}$ & $\begin{array}{l}\text { Patients who chose surgery stated a desire for best chance for cure. Patients who chose BT did so because it was the } \\
\text { least painful, least invasive, promised to have the fewest side effects, was convenient, and avoided surgery. }\end{array}$ \\
\hline Hall et $\mathrm{al}^{9}$ & $\begin{array}{l}\text { Patients who choose prostatectomy are more likely to state that the reason is evidence that it is the best procedure to } \\
\text { cure their cancer. Patients who choose prostate BT are more likely to state that they did so because of side-effect profile. } \\
\text { BT patients were more likely to report their decision was influenced by a physician's preference than were RP patients. }\end{array}$ \\
\hline Holmboe et al $^{10}$ & $\begin{array}{l}\text { The most common dislikes for RP were incontinence and impotence, and the most common like was tumor removal. } \\
\text { The most common dislikes of EBRT were long duration of treatment and diffuse targeting. The most common likes for } \\
\text { BT were short duration of treatment, noninvasive, and focused targeting, while weak evidence was cited } \\
\text { as a dislike. Intrinsic characteristics of treatment were cited more commonly than likelihood of side effects as a reason } \\
\text { for choosing treatment. }\end{array}$ \\
\hline Ihrig et al" & $\begin{array}{l}\text { Concerns for possible treatment side effects were cited as a reason for choosing EBRT. Patients who chose RP were } \\
\text { more likely to cite personal beliefs regarding surgery as a reason. }\end{array}$ \\
\hline Mazur et al ${ }^{12}$ & $\begin{array}{l}\text { Most patients who preferred RP reported that their choice was most influenced by desire for complete cancer } \\
\text { removal. Most patients who chose AS reported that avoiding surgical complications was their top priority. }\end{array}$ \\
\hline Mazur et $\mathrm{al}^{13}$ & $\begin{array}{l}\text { One quarter of men in this study preferred AS even when RP was assumed to have a I0-year survival benefit. } \\
\text { Older patients were also more likely to prefer AS. }\end{array}$ \\
\hline Ramsey et $\mathrm{al}^{14}$ & $\begin{array}{l}\text { Men who choose RP are less likely to rank chances of problems with sexual function as very important. Men who rank } \\
\text { convenience as a priority are more likely to choose BT. }\end{array}$ \\
\hline Sidana et al $^{15}$ & $\begin{array}{l}\text { Doctor's recommendation was the most commonly cited reason for choosing a treatment. Among those who chose } \\
\text { RP over RT, the most common reasons were best chance of cure, doctor recommended, and young age. Among those } \\
\text { who chose RT over RP, the most common reasons were less invasive and fewer side effects. }\end{array}$ \\
\hline Sommers et al $^{16}$ & $\begin{array}{l}\text { The strongest predictor of management choice was type of physician seen when the survey was administered. } \\
\text { QALYs for health states did not predict treatment choice. }\end{array}$ \\
\hline Steginga et al $^{17}$ & $\begin{array}{l}\text { Open-ended questions revealed that the most concerning side effects for RP are incontinence and impotence. } \\
\text { The most concerning side effects for EBRT are bowel problems and skin burns. }\end{array}$ \\
\hline van Tol-Geerdink et al ${ }^{18}$ & $\begin{array}{l}\text { Patients preferring BT valued sexual problems and convenience of the treatment more than patients choosing RP } \\
\text { or EBRT. }\end{array}$ \\
\hline Xu et $\mathrm{al}^{19}$ & Perceptions of treatment efficacy and risks of side effects were the most influential contributors to patient preferences. \\
\hline Xu et $\mathrm{al}^{20}$ & $\begin{array}{l}\text { Knowledge of AS is limited, and some men yield to pressure from family members and physicians to choose active } \\
\text { treatment over AS. }\end{array}$ \\
\hline Zeliadt et $\mathrm{al}^{2 !}$ & $\begin{array}{l}\text { Men who were concerned about the burden of treatment were more likely to prefer options other than RP. Men who } \\
\text { prioritized treatment efficacy were more likely to consider only RP. }\end{array}$ \\
\hline Zeliadt et $\mathrm{al}^{22}$ & Men who prioritized risk of adverse effects were more likely to prefer nonsurgical options. \\
\hline
\end{tabular}

Abbreviations: AS, active surveillance; BT, brachytherapy; EBRT, external beam radiation therapy; QALYs, quality-adjusted life years; RP, radical prostatectomy. 


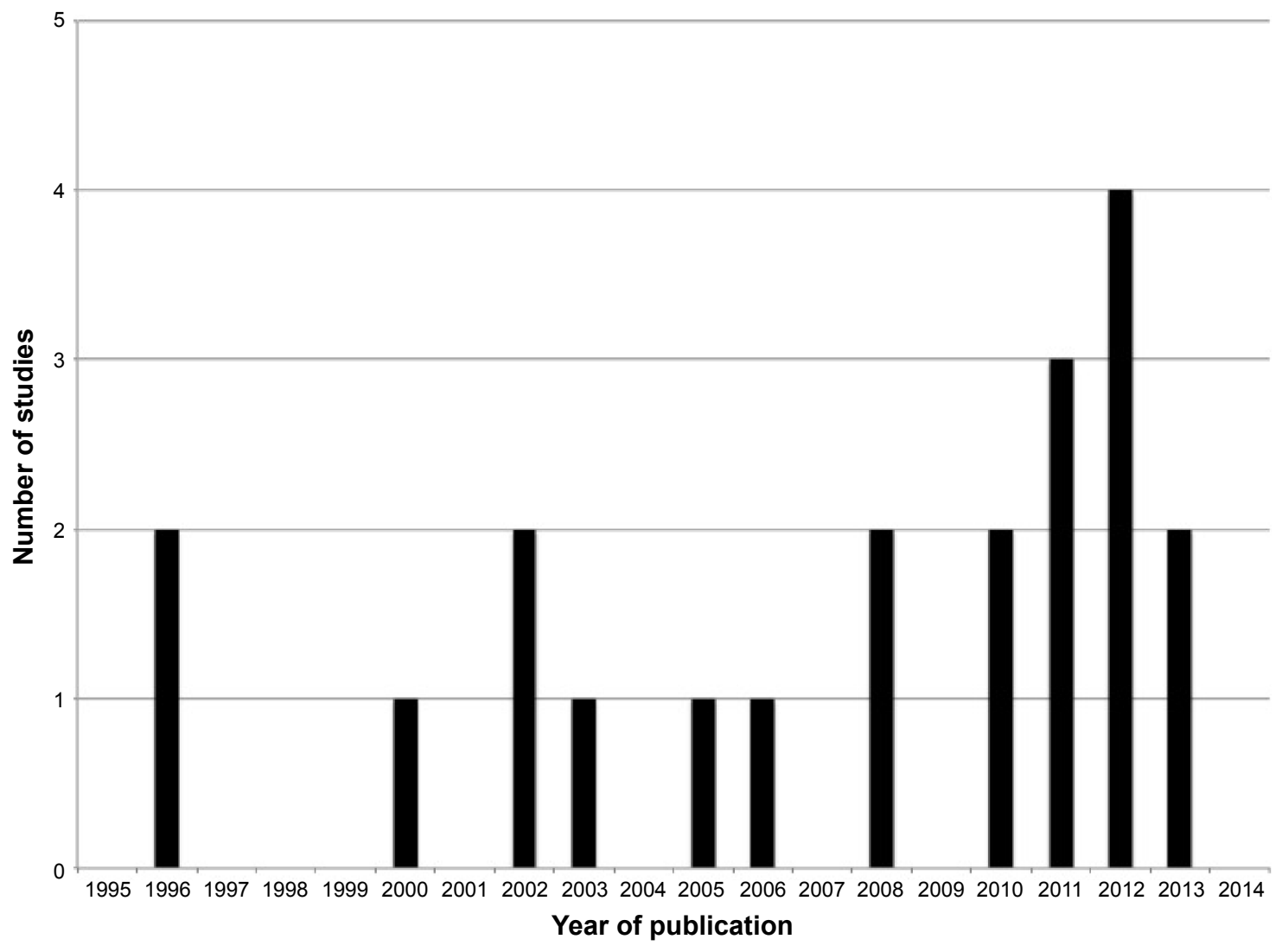

Figure SI The number of studies included per publication year among the final set of 21 articles.

\section{References}

1. Joy SM, Little E, Maruthur NM, et al. Patient preferences for the treatment of type 2 diabetes: a scoping review. PharmacoEconomics. 2013;31:877-892.

2. Anandadas CN, Clarke NW, Davidson SE, et al. Early prostate cancer - which treatment do men prefer and why? BJU Int. 2011; 107(11):1762-1768.

3. Berry DL, Ellis WJ, Russell KJ, et al. Factors that predict treatment choice and satisfaction with the decision in men with localized prostate cancer. Clin Genitourin Cancer. 2006;5(3):219-226.

4. Bosco JL, Halpenny B, Berry DL. Personal preferences and discordant prostate cancer treatment choice in an intervention trial of men newly diagnosed with localized prostate cancer. Health Qual Life Outcomes. 2012;10:123-123.

5. Chapple A, Ziebland S, Herxheimer A, et al. Is 'watchful waiting' a real choice for men with prostate cancer? A qualitative study. BJU Int. 2002;90:257-264.

6. Davison BJ, Breckon E. Factors influencing treatment decision making and information preferences of prostate cancer patients on active surveillance. Patient Educ Couns. 2012;87:369-374.

7. de Bekker-Grob EW, Bliemer MC, Donkers B, et al. Patients' and urologists' preferences for prostate cancer treatment: a discrete choice experiment. Br J Cancer. 2013;109:633-640.

8. Gwede CK, Pow-Sang J, Seigne J, et al. Treatment decision-making strategies and influences in patients with localized prostate carcinoma. Cancer. 2005;104(7):1381-1390.

9. Hall JD, Boyd JC, Lippert MC, et al. Why patients choose prostatectomy or brachytherapy for localized prostate cancer: results of a descriptive survey. Urology. 2003;61:402-407.

10. Holmboe ES, Concato J. Treatment decisions for localized prostate cancer: asking men what's important. J Gen Intern Med. 2000; 15: 694-701.
11. Ihrig A, Keller M, Hartmann M, et al. Treatment decision-making in localized prostate cancer: why patients chose either radical prostatectomy or external beam radiation therapy. BJU Int. 2011;108:1274-1278.

12. Mazur DJ, Hickam DH. Patient preferences for management of localized prostate cancer. West J Med. 1996;165(1-2):26-30.

13. Mazur DJ, Hickam DH, Mazur MD. How patients' preferences for risk information influence treatment choice in a case of high risk and high therapeutic uncertainty: asymptomatic localized prostate cancer. Med Decis Making. 1999;19(4):394-398.

14. Ramsey et al.

15. Sidana A, Heranndez DJ, Feng Z, et al. Treatment decision-making for localized prostate cancer: what younger men choose and why. Prostate. 2012;72(1):58-64.

16. Sommers BDB, Beard CJ, D'Amico AV, Kaplan I, Richie JP, Zeckhauser RJ. Predictors of patient preferences and treatment choices for localized prostate cancer. Cancer. 2008;113(8):2058-2067.

17. Steginga et al.

18. van Tol-Geerdink JJ, Willem Leer J, Weijerman PC, et al. Choice between prostatectomy and radiotherapy when men are eligible for both: a randomized controlled trial of usual care vs decision aid. BJU Int. 2013;111(4):564-573.

19. Xu et al.

20. Xu J, Neale AV, Dailey RK, Eggly S, Schwartz KL. Patient perspective on watchful waiting/active surveillance for localized prostate cancer. J Am Board Fam Med. 2012;25(6):763-770.

21. Zeliadt SB, Moinpour CM, Blough DK, et al. Preliminary treatment considerations among men with newly diagnosed prostate cancer. Ame J Manag Care. 2010;16(5):e121-e130.

22. Zeliadt SB, Ramsey SD, Potosky AL, et al. Association of preexisting symptoms with treatment decisions among newly diagnosed prostate cancer patients. Patient. 2008;1(3):189. 
Patient Preference and Adherence

Dovepress

\section{Publish your work in this journal}

Patient Preference and Adherence is an international, peer-reviewed, open access journal that focuses on the growing importance of patient preference and adherence throughout the therapeutic continuum. Patient satisfaction, acceptability, quality of life, compliance, persistence and their role in developing new therapeutic modalities and compounds to optimize

Submit your manuscript here: http://www.dovepress.com/patient-preference-and-acherence-journa clinical outcomes for existing disease states are major areas of interest for the journal. This journal has been accepted for indexing on PubMed Central. The manuscript management system is completely online and includes a very quick and fair peer-review system, which is all easy to use. Visit http://www. dovepress.com/testimonials.php to read real quotes from published authors. 